\title{
Como ensinar História em tempos de avanço conservador? Conversas com estudantes de Licenciatura do Rio de Janeiro'
}

\author{
How to teach History in times of conservative advance? Conversations \\ with undergraduate students from Rio de Janeiro
}

\section{Pâmella Santos dos Passos* Luciana de Sá Guigues Almeida**}

\begin{abstract}
RESUMO: O presente artigo busca dar visibilidade às análises de uma pesquisa desenvolvida no âmbito da Iniciação Científica do Instituto Federal do Rio de Janeiro (IFRJ) e do estágio de Pós-Doutorado em Educação na Universidade Federal Fluminense (UFF), realizado pela orientadora da referida pesquisa. A partir de alguns exemplos de pronunciamentos públicos de autoridades políticas brasileiras acerca de fatos e interpretações históricas, discutiremos o conceito de conservadorismo, analisando seu avanço recente no país, bem como seus impactos no campo educacional. Num segundo momento, a partir da análise de relatos e materiais produzidos pelos alunos do curso de extensão "Os desafios do Ensino de História em Tempos de Conservadorismo", voltado para estudantes de licenciatura em História e realizado no IFRJ em 2019, propomos refletir sobre táticas inventivas e de superação desse fenômeno de ódio aos professores, somado a desvalorização do lugar da Escola e da Universidade como produtor do conhecimento. Em seguida, debruçando-nos em narrativas, registros e planejamentos de atividades elaborados pelos licenciandos cursistas, buscaremos apontar alguns desafios para o Ensino de História em tempos de conservadorismos.

Palavras chave: Ensino de História; Conservadorismo; Formação de Professores; Narrativas; Táticas.
\end{abstract}

ABSTRACT: The present article seeks to give visibility to the analyses of a research developed from a Instituto Federal do Rio de Janeiro's (IFRJ) Scientific Initiation and a Post-Doctorate in Education at the Federal Fluminense University (UFF), carried out by the supervisor of the referred research. Based on some examples of public statements by Brazilian political authorities about historical facts and interpretations, we will discuss the concept of conservatism, analyzing its recent progress in the country, as well as its impacts in the educational

\footnotetext{
1 A pesquisa recebeu financiamento do edital Prociência do IFRJ e bolsa de Iniciação Científica do CNPq.

* Professora do quadro efetivo do Instituto Federal de Educação Ciência e Tecnologia do Rio de Janeiro (IFRJ). Atualmente realiza estágio de Pós Doutorado no Programa de Pós Graduação em Educação da Universidade Federal Fluminense (UFF) Com estágio de Pós Doutorado pelo Programa de Pós graduação em Antropologia Social/ Museu Nacional/ Universidade Federal do Rio de Janeiro(2016). Doutora em História Social pela Universidade Federal Fluminense(2013), mestre em História, área de concentração História Política, pela Universidade do Estado do Rio de Janeiro(2008) e graduada em História pela Universidade do Estado do Rio de Janeiro(2006), Possui experiência na área de História e Ensino de História, com ênfase em História do Brasil República. Desenvolveu pesquisas sobre Juventudes, Cultura Popular e Favelas Cariocas, Anticomunismo no Brasil, Ensino de História em Escolas Técnicas. Atualmente pesquisa sobre os impactos do Conservadorismo no Ensino de História e coordena projetos de extensão na área de Educação e Direitos Humanos. E-mail: pamella.passos@ifrj.edu.br ORCID: https://orcid.org/0000-0001-9759-6100

** Licencianda de História na Universidade Federal Fluminense (UFF). E-mail: lucianaguigues@gmail.com ORCID: https://orcid.org/0000-0002-1933-8840
} 
field. In a second step, based on the analysis of reports and materials produced by the students of the extension course "The challenges of History Teaching in Conservative Times", aimed at undergraduate History students and held at IFRJ in 2019, we propose to reflect on inventive tactics to overcome this phenomenon of hatred of teachers, added to the devaluation of School's and University's environment as knowledge producers. Then, focusing on narratives, records and activity plans prepared by the undergraduate students, we will seek to point out some challenges for the Teaching of History in conservative times.

Keywords: History Teaching; Conservatism; Teacher Training; Narratives, Tatics.

\section{O Ensino de História em tempos de conservadorismo: compre- endendo o contexto brasileiro}

Discutir conservadorismo no contexto político brasileiro nos remete a inúmeros períodos da história de nosso país, no entanto, queremos no espaço deste artigo demarcar uma temporalidade a fim de que possamos nos aprofundar na análise específica de seus desdobramentos no ensino de história, em especial, na formação de professores. Assim sendo, compreendemos o ano de 2014 como marco inicial de uma escalada conservadora, pois como aponta Rayani Mariano dos Santos:

O Congresso eleito em 2014, que tomaria posse em 2015, foi o mais conservador das últimas décadas. Com o início da nova legislatura em 2015, o deputado Eduardo Cunha (Partido do Movimento Democrático Brasileiro - PMDB/RJ) conseguiu se eleger como presidente da Câmara, representando interesses tanto empresarias quanto religiosos. Cunha é evangélico e fortaleceu durante seu mandato pautas conservadoras, como o Estatuto da Família. Foi em 2015 que, pela primeira vez, a Frente Parlamentar Evangélica conseguiu se formalizar oficialmente (SANTOS, 2020.p.63).

Nesse contexto o tema da defesa da família e dos valores morais ganhou protagonismo no cenário político brasileiro dialogando intensamente com as camadas populares do país, acionando medos, tradicionalismos e um pânico moral (MENDONÇA, 2018). Os ataques ao que compreendemos como educação crítica e democrática tiveram como porta de entrada a luta contra a suposta "ideologia de gênero". E assim, sob o argumento de "proteção às crianças" iniciou-se uma perseguição a temas relacionados às mulheres e à população LGBTQI. Consequentemente, os educadores que insistiam em abordar tais temáticas receberam, por parte dos discursos conservadores que os atacavam, a alcunha de "doutrinadores".

$\mathrm{Na}$ linha de frente deste discurso conservador de ataque aos professores e à educação democrática está o Movimento Escola Sem Partido (ESP). Criado em 2004, este vem ganhando adeptos na sociedade e representantes na política institucional, como Câmaras Municipais, Congresso Nacional e atualmente, a presidência da República. Tal movimento possui uma chave de leitura própria para a compreensão do fenômeno educacional brasileiro, chave esta que, por ser considerada por vezes absurda, não foi confrontada com a devida seriedade (PENNA, 2017).

O ESP não é o único braço do que denominados aqui de discursos conservadores em ascensão no Brasil, mas sem dúvida constitui grande visibilidade deste segmento ideológico, que, ao se consolidar no país, dá respaldo a falas de desqualificação dos professores, 
como a que observamos abaixo:

\section{Imagem 1}

Publicação do deputado federal Daniel Silveira em sua conta pessoal no Twitter em 31 de março de $2019^{2}$

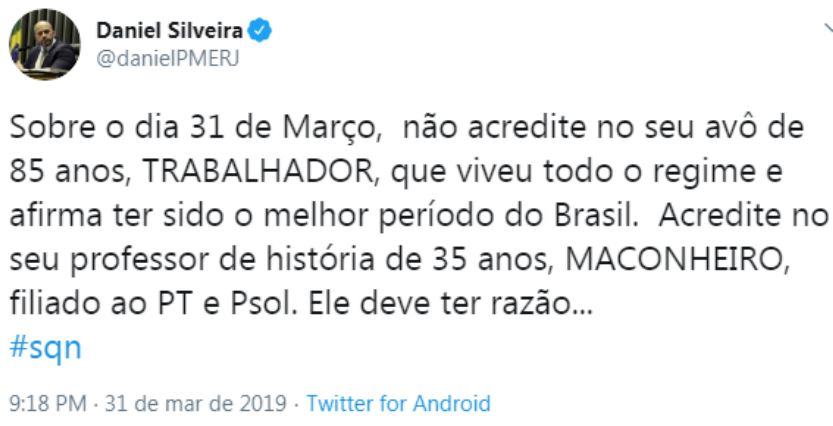

Observamos neste fragmento que a idade é usada pelo deputado como um argumento que reforça a veracidade daqueles que viveram mais, nesse sentido, os 85 anos do avô em questão se sobrepõem aos 35 do professor. Além disso, o parlamentar constrói discursivamente a oposição entre trabalhador e maconheiro, criando um cenário de desqualificação e não reconhecimento do ofício do professor de História, invalidando as informações por ele fornecidas. O uso do termo "maconheiro", de conotação pejorativa e usado para nomear usuários de substâncias ilícitas no território nacional, ganha especial destaque neste contexto. Cabe aqui enfatizar que tal estratégia discursiva foi amplamente utilizada pelo Instituto de Pesquisas e Estudos Sociais (Ipês) nos anos que antecederam o golpe de 1964. Buscando criar um cenário de oposição entre democracia e ditadura, os materiais ipesianos prepararam o terreno para a tomada de poder perpetrada pelos militares em $1^{\circ}$ de abril de 1964.

Ao produzir e veicular textos anticomunistas, o Ipês não só buscava criar uma dada identidade do que era ser anticomunista, como também dava visibilidade a uma "comunidade" anticomunista que sustentava tais reflexões e propostas, composta, entre outros, pelos membros do Ipês. Ou seja, a produção de textos anticomunistas, circulando em diferentes meios, como boletins, panfletos, programas televisivos, entre outros, ao colocar em cena o combate ao comunismo, materializava uma luta que supostamente se daria entre "os regimes orientais que escravizam o homem" e "as democracias ocidentais". Essa luta foi produzindo modos de ser e agir anticomunistas, dando visibilidade a uma comunidade de sustentação das referidas propostas e reflexões: os grupos anticomunistas (PASSOS, 2017, p. 69).

Em processo similar identificamos a movimentação discursiva que busca criar oposições entre trabalhadores e professores, estes últimos tidos como "pseudo-intelectuais" e "maconheiros". Interessa observar que o foco do que aqui denominamos de discurso conservador não se restringiu apenas às temáticas de gênero, uma vez que episódios históricos foram questionados em suas análises reconhecidas no campo historiográfico.

A postagem do deputado federal Daniel Silveira não foi isolada, outros parlamentares também se pronunciaram no mesmo sentido de defender a tomada do poder pelos militares

2 Disponível em: https://twitter.com/danielPMERJ/status/1112509408427343872 Acesso em 12 de jun de 2020. 
em 1964. Cabe destacar que em 2019, ano de tais postagens, o referido episódio histórico completava 55 anos e setores militares e do governo defendiam a existência de uma comemoração para este fato.

Imagem 2

Imagem da chamada da reportagem do Globo $^{3}$

\section{Bolsonaro determina que militares celebrem golpe de 64}

A informação foi confirmada na tarde desta segunda-feira pelo porta-voz da Presidência, Otávio do Rêgo Barros

A celeuma gerada pelo incentivo do chefe do executivo à comemoração do golpe de 1964 levou a Procuradoria Federal dos Direitos do Cidadão (PFDC), ligada ao Ministério Público Federal, a emitir parecer contrário a tais comemorações. Segundo a PFDC, não há dúvidas de que o golpe de Estado de 1964 foi um rompimento violento e antidemocrático da ordem nacional. Como aponta outra reportagem, do portal $\mathrm{R} 7^{4}$, o exército brasileiro estava proibido de comemorar esta data desde 2011 por determinação da presidente da época, Dilma Rousseff. A diferença de postura entre os governos de 2011 e 2020 é um importante indicador acerca do apreço à democracia e suas instituições republicanas no Brasil, bem como do avanço conservador no país.

Corroboramos com outros trabalhos acadêmicos que afirmam que atualmente vivenciamos um recrudescimento do discurso conservador na sociedade brasileira, o qual vem penetrando com força nas instituições escolares (SEPULVEDA \& SEPULVEDA, 2016 p. 77). Assim como José Sepulveda e Denize Sepulveda (2016; 2019) entendemos o conservadorismo político por contrarrevolucionário e antidemocrático, pautado no tradicionalismo. Portanto, o identificamos na atual conjuntura brasileira, em que presenciamos a retirada gradual de direitos sociais e trabalhistas, o avanço do antiintelectualismo, bem como a comemoração do período ditatorial, além da naturalização de desigualdades que remetem à antiga ordem social.

Para os objetivos de nossa pesquisa - em especial no que tange ao foco deste artigo sobre o avanço conservador e seus impactos do Ensino de História, com ênfase na formação de professores - vale abordar novamente duas práticas do atual governo. São elas: a sistemática defesa da ditadura por parte do atual governo e sua tentativa de deslegitimação do saber historiográfico produzido nos espaços formais de educação, tais como Universidades e Escolas.

A exemplo disso podemos citar ainda a fala do deputado federal Eduardo Bolsonaro que, ao divulgar uma exibição do filme 1964: O Brasil entre armas e livros, afirmou que o mesmo conta a realidade do Brasil e desagrada os professores de História que, segundo ele, tentam

\footnotetext{
3 Reportagem completa disponível em: https://oglobo.globo.com/brasil/bolsonaro-determina-que-militares-celebrem-golpe-de-64-23549592 Acesso em 14 jun. 2020.

4 Reportagem completa disponível em https://noticias.r7.com/brasil/exercito-brasileiro-comemoragolpe-militar-a-pedido-de-bolsonaro-31032019-1 Acesso em 14 jun. 2020.
} 
"enviesar ideologicamente" os alunos..$^{5}$

Neste mesmo sentido, Ricardo Veléz - ex Ministro da Educação - declarou em entrevista que pretendia realizar mudanças progressivas nos livros didáticos. Isso porque, segundo ele, a Ditadura foi um "regime democrático de força" e os historiadores devem "reconstituir" esse passado para que tenhamos consciência do que realmente fomos, do que somos e do que seremos.

Em entrevista ao Valor, nesta quarta-feira (3), o ministro da Educação, Ricardo Vélez Rodríguez, disse que "haverá mudanças progressivas" nos livros didáticos para que "as crianças possam ter a ideia verídica, real", do que foi a sua história. Referia-se à maneira como o golpe militar de 1964 e a ditadura são retratados, hoje, nas escolas.

Vélez discorda dessas duas premissas: para ele, não houve golpe em 31 de março daquele ano nem o regime que o sucedeu foi uma ditadura. ${ }^{6}$

O posicionamento acima expresso pelo então Ministro da Educação contraria todas as pesquisas historiográficas referendadas academicamente no Brasil, as quais afirmam a tomada de poder pelos militares em 1964 como golpe, seguida de uma ditadura. Mas a pergunta que lançamos aqui é: o que torna possível e permite que esta fala seja dita por um representante do governo em uma democracia? O que dá sustentação e legitima o discurso de incredulidade da pesquisa científica e desqualificação do lugar dos professores e da escola? A nosso ver é a ascensão e o fortalecimento do conservadorismo no Brasil. Mas o que entendemos por Discurso Conservador/Conservadorismo?

Cabe historicizar que a corrente política conservadora tem suas origens no início da Idade Contemporânea, no momento pós Revolução Francesa. Esta, por ter engendrado bruscas rupturas com a ordem social proveniente do Antigo Regime, obteve como reação severas críticas, em especial do filósofo Edmund Burke (1982), que ficou conhecido como o pai do conservadorismo político. Burke defendia que a antiga ordem se fundamentava na vontade de um criador divino, e por isso devia ser respeitada.

Tecendo importantes críticas à visão trazida por Burke, José Antonio Sepulveda e Denize Sepulveda apresentam o conservadorismo como um discurso carregado de senso comum e por isso mesmo extremamente sedutor. Para os pesquisadores, a principal arena de disputa do conservadorismo é o campo da cultura, sendo assim, passado e tradição estariam em disputa (SEPULVEDA; SEPULVEDA, 2016).

Nos exemplos que destacamos anteriormente, com produção de filmes e desejo de novos livros didáticos, percebemos este ímpeto pela produção de novas e opostas leituras sobre um passado recente de nosso país. Cabe, porém, destacar que é importante não compreender o conservadorismo apenas como um movimento de reação a mudanças, como se deu com a ruptura empreendida pela Revolução Francesa e em outros momentos históricos, como aponta Hirschman (1992) no que chama de as "três reações". Estas seriam as três principais ondas conservadoras, que, segundo o autor, sucederam como resposta a momentos de grande avanço social. Além da Revolução de 1789, trata-se dos avanços da participação

5 Reportagem completa disponível em: https://g1.globo.com/df/distrito-federal/noticia/2019/11/07/eduardo-bolsonaro-faz-convite-para-exibicao-gratuita-de-filme-sobre-ditadura-nodf-em-evento-sem-autorizacao.ghtml Acesso em 09 de jun de 2020.

6 Reportagem completa disponível em: https://valor.globo.com/politica/noticia/2019/04/03/velezquer-alterar-livros-didaticos-para-resgatar-visao-sobre-golpe.ghtml Acesso em 09 de jun de 2020. 
popular na política no século XIX, e do WalfareState já no século XX.

Neste sentido, os Sepulveda destacam que o conceito de conservadorismo é carregado de sentidos e que entendê-lo somente a partir de um caráter reativo reduz as práticas conservadoras à existência de práticas progressistas (SEPULVEDA; SEPULVEDA, 2016). Corroboramos com tal visão, entendendo também que o conservadorismo produz conhecimento e agentes políticos, além de possuir partidos com propostas e agendas definidas. Enxergar esse movimento como mera reação é perigoso, pois pode implicar o não reconhecimento de suas teses conservadoras e capacidade de ação.

Compreendemos então o conservadorismo como uma narrativa que naturaliza desigualdades e que vem ganhando espaço no campo educacional brasileiro como nos apontam os pesquisadores no assunto:

O conservadorismo se caracterizou então por um discurso contrário a ganhos e direitos sociais; se sustenta na anti-intelectualidade, na antirracionalidade, na luta contra qualquer forma de revolução e contra a democracia, tornando-se uma forte narrativa em disputa no campo da cultura (SEPULVEDA; SEPULVEDA, 2019, p.875).

Frente a essas fortes narrativas nos resta "escovar a história a contrapelo", produzir narrativas que desnaturalizem tais desigualdades, tornar comunicáveis experiências silenciadas (BENJAMIN, 1994). Buscamos cumprir tal objetivo no curso promovido pela pesquisa em 2019, que teve como público-alvo estudantes de licenciatura em História. Dialoguemos com as narrativas produzidas nesses encontros.

\section{A experiência de um curso com licenciandos em História}

Como nos aponta o professor da UFRGS, Fernando Nicolazzi, em seu vídeo "O Brasil Paralelo produz História?" , os autores desses discursos que aqui nomeamos de conservadores produzem uma narrativa sobre o passado. Mas que narrativa seria esta? Que desdobramentos destas narrativas afetam a vida dos professores de história?

Cabe aqui destacar,ainda que de forma breve, que o Brasil Paralelo ${ }^{8}$ foi criado em 2016 em Porto Alegre a partir de empresários e empreendedores os quais, na visão do grupo, "têm por objetivo combater narrativas esquerdistas". No entanto, para o Jornal Folha de São Paulo:

\footnotetext{
7 Vídeo disponível em: https://www.youtube.com/watch?v=R71LxS5FhD8 Acesso em 10 de jun de 2020.

8 Maiores informações sobre o grupo e suas ações disponíveis em: https://site.brasilparalelo.com.br/home/ Acesso em 10 de jun de 2020. 
Imagem 3

Imagem da chamada da reportagem ${ }^{9}$

CINEMA

\title{
Produtora Brasil Paralelo revisa a história em filmes e livros com visão de direita
}

\author{
Grupo gaúcho faz frente quanto ao que acredita ser uma \\ predominância do ideário da esquerda no universo da cultura
}

De acordo com o pesquisador Nicolazzi, a partir de uma campanha de arrecadação, a iniciativa de 2016 capacitou financeiramente o grupo para inúmeras produções audiovisuais que atualmente são divulgadas no site do Brasil Paralelo. Outra vez fica patente uma interessante semelhança desta ação com aquela realizada pelo Instituto de Pesquisas e Estudos Sociais (Ipês) na década de 1960, sobretudo a partir de seus filmes, como aponta a pesquisa "Propaganda e Cinema a serviço do golpe", realizada pela jornalista Denise Assis e publicada pela FAPERJ ${ }^{10}$ em 2001.

No espaço deste artigo não nos aprofundaremos na análise do Brasil Paralelo e suas produções; no entanto, queremos corroborar com a afirmação de Fernando Nicolazzi, para quem as narrativas produzidas pelo Brasil Paralelo têm como consequência um esvaziamento dos espaços formais de produção do conhecimento, como Escolas e Universidades. É na contramão deste esvaziamento que propusemos um curso voltado para estudantes de Licenciatura em História, produzindo assim um espaço para troca de saberes, narrativas e táticas.

Intitulado "Os desafios do Ensino de História em tempos de conservadorismo", o curso contou com 05 (cinco) encontros presenciais e algumas atividades à distância como produção de relatos dos encontros e elaboração de planos de aula e materiais didáticos sobre temas considerados sensíveispelos alunos (PASSOS; GUIGUES, 2020).

Como destacamos no subtítulo deste item, foi um curso com os licenciandos e não para eles. A distinção da preposição utilizada aponta nossa perspectiva educacional. Acreditamos na troca, no dialogismo, na pedagogia crítica. Nosso objetivo neste curso era escutar destes professores e professoras de História em formação quais são suas angustias e expectativas, para assim pensar, conjuntamente, saídas e resistências possíveis.

Primeiramente, cabe destacar que em conjunto com os licenciandos definimos o entendimento sobre o que são "temas sensíveis". Em nossas conversas, tema sensível é aquele que, apesar de constar no conteúdo curricular de História, desperta desconforto, insegurança e por vezes medo nos futuros docentes, tendo em vista os ataques e desqualificações feitas aos professores - como nos exemplos trazidos anteriormente em nosso artigo.

Ressaltamos, porém, que na turma do curso ninguém relatou que não daria aula sobre algum tema por insegurança ou medo, pelo contrário, o que percebemos foi uma vontade de fortalecimento e maiores conhecimentos para preparar uma aula ainda melhor sobre tais te-

\footnotetext{
9 Reportagem completa disponível em: https://www1.folha.uol.com.br/ilustrada/2019/08/produtora-brasil-paralelo-revisa-a-historia-em-filmes-e-livros-com-visao-de-direita.shtml Acesso em 10/06/2020.

10 Fundação Carlos Chagas Filho de Amparo à Pesquisa do Estado do Rio de Janeiro.
} 
máticas. Nesse sentido, inferimos uma disposição para o embate e a resistência presente nestes futuros professores de História.

Como propunha uma das atividades do curso, cada aluno deveria escolher um tema considerado por ele "sensível" ou "polêmico" e justificar tal escolha. Posteriormente, eles enviaram planos de aula e materiais didáticos produzidos para abordar essas temáticas. A seguir apresentamos um quadro com os temas selecionados e as justificativas apresentadas.

\section{Tabela de Temas sensíveis para plano de aulas}

\begin{tabular}{|c|c|}
\hline Tema da aula & Justificativa da escolha do tema \\
\hline $\begin{array}{l}\text { Escravidão moderna: a en- } \\
\text { trada dos africanos no } \\
\text { Brasil }\end{array}$ & $\begin{array}{l}\text { Desconstruir a ideia de que "os negros escravizaram os negros", ressaltando as diferenci- } \\
\text { ações entre tribos e etnias africanas e apresentar as distinções entre a escravidão em África } \\
\text { (anterior à entrada do europeu) e a escravidão nas colônias. }\end{array}$ \\
\hline $\begin{array}{l}\text { Fake News articulada ao } \\
\text { tema da escravidão }\end{array}$ & $\begin{array}{l}\text { Tematizar a veracidade de informações que circulam a respeito de lideranças escravas } \\
\text { como Zumbi e afins. }\end{array}$ \\
\hline $\begin{array}{l}\text { Cidadania no Pós-Aboli- } \\
\text { ção }\end{array}$ & $\begin{array}{l}\text { Acredito ser um tema importante, para demonstrar como a construção da cidadania no } \\
\text { momento pós-abolição se reflete até os dias de hoje na maneira como a sociedade pensa } \\
\text { e pratica conceitos como racismo, favela, voto e outros assuntos. }\end{array}$ \\
\hline $\begin{array}{l}\text { Abolição - religiosidades } \\
\text { afro-brasileiras }\end{array}$ & $\begin{array}{l}\text { A marginalização do povo e cultura afro-brasileira, no pós-abolição, é capaz de explicar } \\
\text { relações conflituosas na sociedade atual entre religiões de matriz africana e religiões cristãs, } \\
\text { especialmente nas periferias, sendo um tema delicado para se lidar em sala de aula tanto } \\
\text { pela questão da direção escolar quanto pelos pais dos alunos. }\end{array}$ \\
\hline $\begin{array}{l}\text { Movimento Negro e Fe- } \\
\text { minismo no século XX }\end{array}$ & Este será meu tema de regência no IFRJ no dia 12/1111 \\
\hline Ditadura militar brasileira & Acho importante para fazer relação com hoje. \\
\hline $\begin{array}{l}\text { Os sistemas totalitários no } \\
\text { XX: ditaduras na América } \\
\text { Latina e Brasil }\end{array}$ & Está dentro do currículo do ano escolar. \\
\hline $\begin{array}{l}\text { Redemocratização do Bra- } \\
\text { sil e dos países do Cone } \\
\text { Sul }\end{array}$ & $\begin{array}{l}\text { A temática que é abordada nos conteúdos se resume somente ao Brasil, mas compreen- } \\
\text { dendo todo sistema que interligava as ditaduras do Cone Sul e os EUA, acredito ser im- } \\
\text { portante debater o tema de forma mais plural, para que se possa debater os modos pelos } \\
\text { quais a democracia fora alcançada nas nações. A motivação para essa escolha, dá-se no } \\
\text { contexto atual brasileiro, no qual crescem o número de descrentes na democracia e a } \\
\text { mesma entra em colapso. Creio que esse debate seja primordial e ao mesmo tempo deli- } \\
\text { cado de ser abordado, pois se insere numa temática, na qual inúmeras opiniões são expos- } \\
\text { tas. }\end{array}$ \\
\hline Nazifascismo & $\begin{array}{l}\text { O ressurgimento da ideologia nazifascista e suas novas "caras", no Brasil e no mundo, } \\
\text { disfarçada e escondida num discurso conservador. }\end{array}$ \\
\hline $\begin{array}{l}\text { Nazifascismo e o papel da } \\
\text { memória }\end{array}$ & $\begin{array}{l}\text { Penso que os dois pontos do tema andam juntos, já que o fascismo precisa da criação de } \\
\text { uma memória em heróis nacionais para ser instaurado, por exemplo. Além de que, enten- } \\
\text { der a importância da construção da memória tanto para uma sociedade quanto para a } \\
\text { História é algo que falta no Brasil, principalmente. }\end{array}$ \\
\hline $\begin{array}{l}\text { Ascensão do conservado- } \\
\text { rismo e da direita no } \\
\quad \text { mundo atual }\end{array}$ & $\begin{array}{l}\text { No correr dos últimos anos temos observado uma ascensão dos partidos de direita em } \\
\text { diversos países do mundo. Normalmente esses partidos possuem concepções xenófobas, } \\
\text { militaristas, conservadoras. Isso vem ocorrendo em diversos países como França, Ho- } \\
\text { landa, Inglaterra, Polônia, Hungria, Itália, Brasil, Estados Unidos, Alemanha, Israel, etc. } \\
\text { A intenção da aula é tentar entender por quê isso está ocorrendo e quais seriam as razões } \\
\text { por trás dessa ascensão das direitas no mundo. }\end{array}$ \\
\hline $\begin{array}{l}\text { Aula sobre ascensão do } \\
\text { neoliberalismo e a perda } \\
\text { de direitos }\end{array}$ & $\begin{array}{l}\text { Debater as mudanças ocorridas na conjuntura mundial com a ascensão do neoliberalismo, } \\
\text { tendo a intenção de construir junto com os educandos um reconhecimento do tempo } \\
\text { histórico em que estamos situados e incentivando o entendimento de si como sujeito his- } \\
\text { tórico e agente de mudança. }\end{array}$ \\
\hline Reforma Protestante & Debater sobre a diversidade de crenças e sobre a tolerância religiosa \\
\hline
\end{tabular}

Como foi possível observar no quadro acima, obtivemos 04 (quatro) planos de aula cujos temas se referiam à escravidão ou abolição da mesma - tendo sido essa a temática mais recorrente na turma -, além de 01 (um) plano sobre Movimento Negro no século XX. Mas

${ }^{11} \mathrm{~A}$ licencianda realizava estágio curricular obrigatório no IFRJ e daria esta aula poucas semanas após a conclusão do curso, no dia 12/11/2019. 
porque estes temas foram considerados "sensíveis" ou "polêmicos" pelos licenciandos do curso?

Como é possível observar nas justificativas apresentadas pelos licenciandos que optaram por estas temáticas, tratar de escravidão e/ou abolição em sala de aula pode ser difícil uma vez que está incutida em nossa sociedade atualmente a ideia de que a escravidão empreendida com a colonização europeia não foi tão ruim quanto apontam os livros de História, pois já antes disso "os negros escravizavam os negros". Ou, nas palavras do próprio presidente Jair Bolsonaro, "o português nem pisava na África, eram os próprios negros que entregavam os escravos". ${ }^{12}$

O argumento de que "os negros escravizavam os próprios negros" é facilmente refutado por ampla produção historiográfica que demonstra, a partir de fontes e métodos de investigação histórica, a diferença entre a escravidão realizada nas colônias europeias e aquela praticada no interior do continente africano. No entanto, ignorando estas produções de conhecimento, outras autoridades do atual governo também fizeram declarações falaciosas a respeito da temática da escravidão no Brasil e críticas sobre o Movimento Negro brasileiro, como é o caso do atual presidente da Fundação Cultural Palmares (FCP).

Importante destacar que a Fundação Palmares é uma entidade pública vinculada à Secretaria Especial da Cultura, cujo objetivo é justamente promover a preservação dos valores culturais, sociais e econômicos decorrentes da influência negra na formação da sociedade brasileira. ${ }^{13}$ No entanto, a despeito dos objetivos previstos na lei de criação da Fundação, seu atual presidente, o jornalista Sérgio Camargo, faz declarações públicas negando a existência de um "racismo real" no Brasil e afirmando que a escravidão foi benéfica para os descendentes dos negros escravizados em nosso pais, como podemos observar a seguir:

Imagem 4

Imagem 5

A escravidão foi terrível, mas benéfica para os descendentes. Negros do Brasil vivem melhor que os negros da África.
O Brasil tem racismo nutella. Racismo real existe nos EUA. A negrada daqui reclama porque é imbecil e desinformada pela esquerda.

Publicações de Sérgio Camargo em seu perfil pessoal do Facebook em 27 de agosto e 15 de setembro de $2019^{14}$ - poucos meses antes de sua nomeação para a presidência da Fundação Cultural Pal-

12 Entrevista de Jair Bolsonaro no programa Roda Viva em 30 de julho de 2018. Disponível em: https://youtu.be/vtbXWVEWI88 Acesso em 07 de mai de 2020.

13 LEI No 7.668". www.planalto.gov.br. 22 de agosto de 1988. Disponível em: http://www.planalto.gov.br/ccivil_03/LEIS/L7668.htm Acesso em 07 de mai de 2020.

14 Disponível em: https://www.facebook.com/sergio.camargo.184/posts/2318137664908228 e https://www.facebook.com/sergio.camargo.184/posts/2351837028204958 Acesso em 14 de mai de 2020. 
mares, em novembro do mesmo ano.

Devido a falas deste tipo, uma Ação Popular foi proposta contra a decisão do governo Bolsonaro de tornar Camargo presidente da Fundação Palmares. Em dezembro de 2019, o Juiz da $18^{a}$ Vara Federal do Ceará suspendeu sua nomeação para o cargo, declarando que as publicações do jornalista ofendem o público que deve ser protegido pela Fundação. Contudo, a Advocacia Geral da União (AGU) entrou com recurso e, em fevereiro de 2020, o presidente do Superior Tribunal de Justiça (STJ) restabeleceu a nomeação de Camargo, atendendo a pedido do governo.

Portanto, o jornalista continua na presidência da FCP e segue causando polêmica com suas publicações em redes sociais. Ele inclusive ataca constantemente as figuras que dão nome à Fundação: o Quilombo dos Palmares e Zumbi, o qual acusa, sem nenhum tipo de embasamento documental, de ter sido um "assassino que escravizava negros e raptava mulheres"15. Essa é também a narrativa endossada pela doutora em linguística Mayalu Felix em texto publicado no site da Fundação Palmares, no dia 13 de maio deste ano - aniversário de 132 anos da abolição da escravidão. ${ }^{16}$

Em tal artigo de opinião, que busca apresentar-se como acadêmico, a autora se propõe a "desconstruir o falso herói". No entanto, não apresenta fontes históricas que embasem seus argumentos, tão pouco dialoga com a vasta publicação historiográfica sobre o tema apresentando referências bibliográficas consistentes. Foi justamente sobre isso que escreveu um dos alunos de nosso curso ao justificar a escolha do tema sobre Fake News articulada à escravidão para seu plano de aula: "Tematizar a veracidade de informações que circulam a respeito de lideranças escravas como Zumbi e afins".

Em uma das páginas do material didático elaborado por este licenciando o tema era "Usos da História" e trazia os seguintes questionamentos:

1. O Fato de existir escravidão em países africanos é um tema central na discussão histórica sobre escravização no Brasil?

2. Especular que, por analogia, Zumbi seria uma liderança quilombola praticante de escravização atende a quais objetivos? (A.A., 2019) ${ }^{17}$

No espaço deste artigo não nos cabe apresentar qual visão histórica acerca de Zumbi ou do Quilombo de Palmares adotamos. No entanto, assim como o licenciando em seu material didático, propomos a reflexão acerca de quais interesses movem figuras públicas e autoridades do atual governo, incluindo o presidente da fundação encarregada de preservar a cultura afro-brasileira e seus valores, a se opor ao conhecimento historiográfico referendado acerca desta temática.

\footnotetext{
15 Publicação de Sérgio Camargo em seu perfil pessoal no Facebook em 13 de Janeiro de 2020. Disponivel em: https://www.facebook.com/permalink.php?story_fbid=1029831017372394\&id= 100010365164255 Acesso em 14 de mai de 2020.

16 FELIX, Mayalu. A NARRATIVA MÍTICA DE ZUMBI DOS PALMARES. Disponível em: http://www.palmares.gov.br/wp-content/uploads/2020/02/A-NARRATIVA-M\%C3\%8DTICA-DE-ZUMBI-DOS-PALMARES.pdf Acesso em 14 de mai de 2020.

17 Trecho do slide elaborado por um licenciando, como atividade referente à aula por ele planejada. Usaremos siglas no lugar dos nomes para preservar a identidade dos participantes do curso.
} 
Tais narrativas insistem em apontar a existência da escravidão no continente africano antes da colonização europeia como fator que minimiza ou desresponsabiliza as nações da Europa pelo processo violento da escravidão em suas colônias.Cabe aqui destacar, como bem fazem os licenciandos que optaram por este tema, que há enormes diferenças entre esses processos de escravidão. De forma muito rápida, podemos apontar que a escravidão por pilhagem ou dívida, independentemente da cor da pele, era a praticada na África, enquanto que a escravidão negra, oriunda de um tráfico de escravizados, era a implementada nas colônias europeias.

Outro licenciando, que optou por abordar "Cidadania no Pós-Abolição", justificou sua escolha alegando a importância da análise deste processo histórico na reflexão acerca de como a sociedade, até os dias de hoje, pensa e pratica conceitos como racismo. Tal aluno propôs para sua aula uma metodologia de análise de sambas enredo. Os sambas selecionados por ele abordam como a Lei Áurea não representou uma abolição total das condições perversas e cruéis que afetavam a população afro-brasileira. Vale trazer os trechos selecionados pelo licenciando e sua proposta de análise:

GRES Estação Primeira de Mangueira (1988) - 100 Anos de Liberdade, Realidade Ou Ilusão:

Será que já raiou a liberdade

Ou se foi tudo ilusão

Será, oh, será

Que a lei áurea tão sonhada

Há tanto tempo assinada

Não foi o fim da escravidão

Hoje dentro da realidade

Onde está a liberdade

Onde está que ninguém viu

Moço

Não se esqueça que o negro também construiu

As riquezas do nosso Brasil

Pergunte ao criador

Quem pintou esta aquarela

Livre do açoite da senzala

Preso na miséria da favela

Autoria: Alvinho, Hélio Turco e Jurandir

Análise proposta: A relação entre o suposto fim da escravidão e a situação vigente no pós abolição, com a continuação do trabalho análogo à escravidão, além da privação das outras liberdades como religiosa, circulação, participação política. É importante frisar o fato de que esse samba rompe com a ideia disseminada na cultura popular de que a Lei Áurea tenha sido um esplendor de liberdade, tendo uma divisão totalmente estruturada e bem divisionada entre o 12 de maio e o 13 de maio.

GRES Paraíso do Tuiuti (2018) - Meu Deus, men Deus, está extinta a escravidão?:

Amparo do Rosário ao negro Benedito

Um grito feito pele do tambor 
Deu no noticiário, com lágrimas escrito

Um rito, uma luta, um homem de cor

E assim, quando a lei foi assinada

Uma lua atordoada assistiu fogos no céu

Áurea feito o ouro da bandeira

Fui rezar na cachoeira contra a bondade cruel

Meu Deus! Meu Deus!

Se eu chorar, não leve a mal

Pela luz do candeeiro

Liberte o cativeiro social

Autoria: Anibal, Cláudio Russo, Jurandir, Moacyr Luz e Zezé.

Análise proposta: Trabalha com o conceito de cativeiro social, onde o negro estaria liberto do cárcere do trabalho forçado, mas relegado à uma "prisão" no que diz respeito aos seus direitos sociais, de pertencer a própria sociedade, condenado a uma marginalização em relação à sociedade, além da repressão às suas manifestações culturais e religiosas. Rompe com o conceito de que a Lei Áurea tenha sido algo dado, no trecho "Deu no noticiário, com lágrimas escrito; Um Rito, uma luta, um homem de cor; E assim, quando a lei foi assinada", visando passar a ideia de que houve luta e resistência antes de se garantir a Lei Áurea, e mesmo depois dela, foi necessário lutar contra a "bondade cruel", já que houve a libertação do cárcere, mas se deixou a população negra refém da própria sorte e do aparato político social que visava lhe negar todos os direitos, negando-lhe assim a condição de ser cidadão, e sua cidadania (J. S., 2019). ${ }^{18}$

Um elemento importante a ser destacado é que o aluno que propôs esta atividade é um jovem negro, compositor de sambas enredos. Assim, vislumbramos nesta proposta uma importante dimensão de representatividade, identidade e afeto.

Diretamente ligada à questão negra no Brasil temos a intolerância religiosa também muito presente em nossa sociedade atualmente, inclusive nas falas do presidente da Fundação Palmares. O mesmo já declarou em rede social que religiões de matriz africana são uma "desgraça que os negros trouxeram ao mundo"19 e que "militantes culpam o 'Jesus branco europeu' pelo sofrimento da África", mas deviam experimentar "deixar a macumba de lado", pois, segundo ele, "países dominados por macumba e por vodu não têm chance de futuro". ${ }^{20}$

A este respeito escreveu o aluno que escolheu tratar sobre a abolição da escravidão e religiosidades afro-brasileiras em seu plano de aula, apontando que a marginalização do negro e de sua cultura após a abolição explica esse tipo de conflito atualmente, entre religiões de matriz africana e religiões cristãs. Destacamos também que a licencianda que optou pelo tema da Reforma Protestante para seu plano de aula justificou a escolha referindo-se à dificuldade de se debater sobre diversidade de crenças e tolerância religiosanas escolas, o que, a nosso ver, se agrava com declarações preconceituosas vindas de autoridades políticas brasileiras.

Outro tema sensível recorrente entre os planos de aula recebidos no curso é o das

\footnotetext{
18 Análises proposta por um licenciando do curso como atividade referente à aula por ele planejada.

19 Publicação de Sérgio Camargo em seu perfil pessoal no Facebook em 1 de outubro de 2019. Disponível em: https://www.facebook.com/100001360504518/posts/2382149521840375/?d=n Acesso em 14 de mai de 2020..

20 Publicação de Sérgio Camargo em seu perfil pessoal no Facebook em 13 de outubro de 2019. Disponível em: https://www.facebook.com/100001360504518/posts/2404902942898366/ ?d=n Acesso em 14 de mai de 2020.
} 
ditaduras militares brasileira e dos demais países latino-americanos e seus processos de redemocratização. Dos três licenciandos que escolheram esse assunto, dois justificaram sua opção devido à atual conjuntura de nosso país, na qual "cresce o número de descrentes na democracia e a mesma entra em colapso", segundo um dos alunos. O mesmo ainda afirmou se tratar de um debate primordial e delicado ao mesmo tempo, uma vez que muitas opiniões divergentes são expostas.

Chamamos atenção para a situação de que o simples fato de posicionamentos contrários serem abordados em sala de aula não deveria ser motivo de medo para os futuros professores (licenciandos). Contudo, especialmente desde a época das eleições presidenciais de 2018, o tema em questão tornou-se demasiadamente polêmico, uma vez que diversas autoridades do presente governo - incluindo o atual ministro e o ex-ministro da educação, além do próprio Presidente da República, dentre vários outros políticos - negam a existência da Ditadura Militar no Brasil. Como já apontamos anteriormente, em alguns casos esses representantes chegam a defender a comemoração da tomada do poder pelos militares em 1964. Tais falas que se contrapõem ao saber histórico produzido academicamente muitas vezes vêm acompanhadas de um discurso de ódio contra os professores - de História, especialmente -, acusados de "doutrinação ideológica".

Como destaca Fernando Penna (2016), esse termo não possui uma definição precisa, e, portanto, permite enquadrar uma ampla gama de casos, sendo utilizado assim em representações da figura do professor que procuram estimular uma onda de ódio, perseguição e ataque contra os mesmos. Na narrativa propagada em grande parte pelo movimento Escola Sem Partido a escola é representada como um espaço terrível de corrupção dos inocentes, sendo os agentes dessa corrupção, os professores (PENNA, 2016, p. 98). Não raro essa suposta "doutrinação ideológica" gera conflitos nas escolas, podendo custar até o emprego de alguns docentes. Foi esse o caso de um professor de educação física de Santa Catarina que, em abril de 2019, foi demitido da escola em que lecionava após trabalhar em aula um texto poético sobre tortura na Ditadura Militar. ${ }^{21}$

Em nossa hipótese, essa é a estratégia utilizada ainda hoje pela extrema direita que ascendeu ao poder. Os professores são apresentados como comunistas doutrinadores, inimigos públicos da nação, gerando medo e ódio que têm como consequência a criação de uma espécie de "cordão sanitário", cuja finalidade seria isolar uma educação supostamente "neutra" da suposta "doutrinação ideológica".

Por isso, enquanto professores devemos lutar para desconstruir essa naturalização da desigualdade, em especial munindo-nos do ensino dos processos históricos que construíram nossa sociedade como a conhecemos hoje. Neste sentido, evocamos Walter Benjamin para afirmar a importância do professor realizar em sala de aula uma "desnaturalização do presente". Cabe ao historiador perceber e mostrar que a história que conhecemos hoje se deu dessa forma por determinados motivos, tais como relações econômicas e sociais de poder. Somos sujeitos de nosso tempo e, portanto, de nossa história. Que possamos escrever outros futuros reinventando nossas práticas, eis o desafio que propusemos neste curso.

${ }^{21}$ Reportagem completa disponível em: https://www.cut.org.br/noticias/sc-professor-e-demitidoapos-trabalhar-texto-sobre-tortura-na-ditadura-militar-32d5 Acesso em 12 de jun de 2020. 


\section{Afirmar o ofício da História: considerações para uma cami- nhada}

Ao final do curso, pedimos aos alunos que respondessem a um questionário de avaliação do mesmo. De acordo com as respostas que obtivemos dos licenciandos, $100 \%$ da turma teve suas expectativas atendidas e recomendaria um curso como esse para seus colegas de graduação. Abaixo seguem alguns trechos dos alunos que relataram sua satisfação:

Acreditava que o curso iria agregar na minha formação profissional e pessoal do ponto de vista relacional principalmente e isso foi atendido. Além das questões referentes aos medos e anseios que foram muito bem debatidas. ${ }^{22}$

Minha expectativa para o curso era que surgissem soluções para o desafio citado no título do mesmo. No entanto, durante o curso eu percebi que a solução é continuar lutando pela educação, para que todos tenham oportunidade de ter e que ela seja de qualidade. Isso já é um grande passo para passar pelos tempos de conservadorismo e diminuir a chance de eles voltarem. Temos que continuar tendo esperança e lutar pelo que acreditamos, juntos. ${ }^{23}$

Como fica evidente pelos relatos acima, o curso buscou discutir sobre os impactos negativos do avanço conservador na educação brasileira, bem como refletir sobre meios de superar esses desafios postos aos professores. Além disso, conseguimos criar um espaço de acolhimento para esses licenciandos, onde pudemos travar tais debates e reflexões de forma frutífera. Juntamente com os alunos, reafirmamos assim o ofício do historiador, especialmente em tempos como os que atravessamos.

A esse respeito se referia uma das perguntas do questionário de avaliação: "Durante as cinco semanas do curso, alguma mudança ou fortalecimento da sua perspectiva sobre o ofício do historiador ocorreu? ". Dos alunos que preencheram o questionário, 70\% responderam a tal questão afirmativamente, e 30\% declararam que não houve nenhuma mudança ou fortalecimento de sua perspectiva nesse aspecto. Este foi o caso de um licenciando que justificou sua resposta da seguinte forma:

Não houve pois eu já tinha essa perspectiva sobre o oficio do historiador como professor pelas aulas que tenho de educação dentro da faculdade, mas me motivou a querer cada vez mais mudanças e impactos. ${ }^{24}$

Em nossa perspectiva é bastante importante dar visibilidade a este relato para afirmar nossa ciência de que, com nossas pesquisas e ações - como este curso -, não pretendemos sanar todas as questões relativas ao avanço conservador no Brasil e seus impactos no ensino de história. No entanto, ainda que o licenciando afirme não ter ocorrido mudanças, ele aponta uma motivação oriunda do curso - o que para nossa análise é bastante relevante.

Outro relato apresentado por uma licencianda, e que trazemos aqui, diz respeito à mudança por ela identificada após a realização dos encontros:

\footnotetext{
22 Relato de aluna não identificada coletado através do formulário de avaliação do curso. Ao preencher tal formulário os alunos não revelaram seus nomes.

23 Relato de aluno não identificado coletado através do formulário de avaliação do curso.

24 Relato de aluno não identificado coletado através do formulário de avaliação do curso.
} 
Eu estava passando por momentos de incerteza em relação a docência, pensando em arranjar alguma maneira de me ligar somente à pesquisa. No entanto, com as aulas do curso isso foi sendo suprimido e senti que tenho o dever de passar o conhecimento que eu obtive e ajudar outros a ter o mesmo..$^{25}$

As colocações desta aluna explicitam uma importante mudança em suas perspectivas. Ao usar o termo "suprimido" em relação às incertezas por ela vivenciadas, acreditamos que, mais do que a resolução total de suas incertezas e inseguranças, ela esteja indicando um processo de fortalecimento ocorrido nos encontros do curso - fator para nós de suma importância.

Além dos relatos que coletamos através do formulário de avaliação do curso, também foi pedido aos alunos que produzissem registros, em formato livre, de cada encontro presencial, como já indicamos no início do artigo. Escolhemos trazer aqui um desenho produzido por uma licencianda como relato da última aula do curso, "Táticas de (Re)invenção no cotidiano escolar: o desafio de Sobreviver e Sonhar".

\section{Imagem 6}

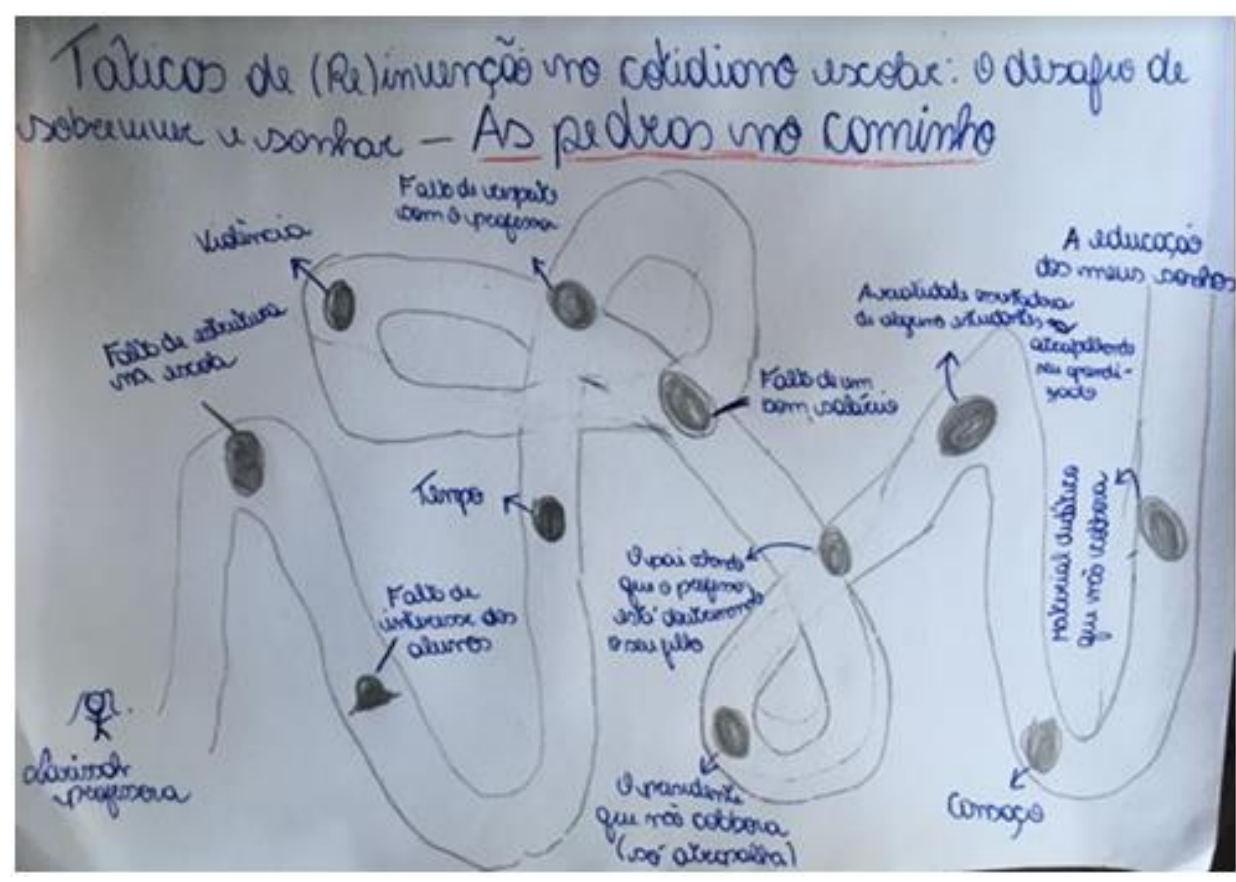

(L.P., 2019) 26

A imagem nos apresenta um caminho bloqueado por pedras, no início identificamos a autora do desenho designada por "professora" e no fim do caminho encontra-se "a educação dos meus sonhos". Em nossa análise, interpretamos que cada uma das pedras representa um obstáculo para se chegar à educação sonhada pela aluna. As pedras têm como legenda: falta de estrutura na escola; falta de interesse dos alunos; tempo; falta de respeito com o

25 Relato de aluna não identificada coletado através do formulário de avaliação do curso.

26 Registro em forma de desenho produzido por uma das licenciandas referente à última aula do curso. 
professor; falta de um bom salário; violência; o presidente que não colabora (só atrapalha); o pai achando que o professor está doutrinando o seu filho; a realidade assustadora de alguns estudantes atrapalhando seu aprendizado; cansaço; material didático que não colabora.

A aula em questão foi ministrada pela professora Nívea Andrade, que,em seu trabalho sobre o cotidiano de uma escola da rede municipal do Rio de Janeiro (2011), discute o conceito de tática desenvolvido por Certeau (1994). Através de tal conceito, o autor buscou nomear as ações que visam enfrentar as circunstâncias sobre as quais não temos uma visão ampla, posto que tais circunstâncias são controladas pelas estratégias dos grupos dominantes (ANDRADE, 2011, p. 29).

Apesar desta opressão exercida através de estratégias por aqueles que possuem o poder hegemônico, há algo que impede o controle total do cotidiano por estes grupos: são as táticas; estas manobras, astúcias ou ações criativas em circunstâncias cotidianas, que permitem a sobrevivência frente àquilo que é imposto pelas estratégias de opressão. Neste sentido, a professora e pesquisadora afirma que, apesar de não serem revolucionárias, as táticas são transformadoras das relações sociais. Isso porque, se por um lado, as táticas não transformam o estatuto do poder, por outro, obrigam os grupos dominantes a permanentemente reformularem suas estratégias (ANDRADE, 2011, p. 31).

No contexto educacional, corroboramos com a visão da autora de que, apesar das legislações e decretos que modificam a estrutura escolar, as táticas de professores e alunos também funcionam como motores de transformações (ANDRADE, 2011, p. 31). Essas táticas geram mudanças que permitem reinventar o cotidiano escolar.

Neste sentido, podemos analisar o desenho trazido acima, referente à aula da professora Nívea Andrade, dialogando com suas elucubrações. Sendo assim, interpretamos que "as pedras no caminho" se referem aos obstáculos presentes no cotidiano escolar que são muitas vezes determinados pelas estratégias dos grupos dominantes. À exemplo disso temos as pedras que se referem à "falta de estrutura na escola", à "falta de um bom salário" e ao "presidente que não colabora (só atrapalha)". No atual contexto brasileiro, tais grupos são enunciadores de discursos conservadores e antiintelectualistas, que vêm desvalorizando o espaço da escola e buscando combater a educação crítica, como já discutimos anteriormente.

Portanto, para trilhar o caminho cheio de pedras, a professora do desenho precisa elaborar táticas de sobrevivência a tais estratégias que criam esses obstáculos. Não sabemos se ao final desta caminhada ela alcançará a educação dos seus sonhos, porém, ela estará caminhando.

Ainda nesta última aula, a professora Nívea realizou com os licenciandos a atividade do Teatro do Oprimido, método teatral criado por Augusto Boal (1991), cujo título homenageia a obra de Paulo Freire, Pedagogia do Oprimido (1987). A atividade consistiu na montagem de três cenas diferentes, encenadas estaticamente por alguns alunos, sem que o resto da turma soubesse do que se tratava. A primeira cena se referia a uma sala de aula de História típica da escola pública no Rio de Janeiro, onde foram feitas referências a violência e intolerância frente a opiniões divergentes. A segunda dizia respeito à sala de aula ideal, remetendo a um ambiente harmônico e libertador. Já a terceira ilustrava o caminho que levaria da primeira à segunda cena, e fez referência à necessidade da educação dialógica, defendida por Freire (1987).

Os alunos que não participaram da encenação deviam tentar adivinhar do que se tratava cada uma das cenas, dialogando entre si. Assim, a partir da atividade e ao longo da 
aula, muitos debates foram suscitados a respeito de táticas de transformações do cotidiano escolar. Sobre tal atividade escreveu um dos alunos em seu registro dessa última aula:

O intuito é questionar uma relação de dominação à qual o sujeito já está acostumado e que impede o desenvolvimento pleno do "oprimido" [...] Acredito que aí deve estar nosso trabalho como professor: libertar o ser humano, desinrejecê-lo, possibilitar novas criações, gerar possibilidades, ir além do que já foi construído ou feito" (J.T., 2019). ${ }^{27}$

Como podemos observar, ao lançar mão do método teatral elaborado por Boal, Nivea Andrade estimulou reflexões acerca das formulações do educador brasileiro Paulo Freire, no que tange a necessidade de uma educação crítica como ferramenta de libertação contra a opressão dos grupos dominantes. Neste sentido, cabe trazer para análise deste artigo o registro de outra licencianda referente à terceira aula do curso, na qual a professora Adriana Facina também discutiu a visão Freireana da Educação:
Por que o patrono da educação brasileira incomoda tanta gente?
A esta indagação, responderei com a frase do nosso patrono: 'Seria uma atitude ingênua esperar que as classes dominantes desenvolvessem uma forma de educação que propor- cionasse às classes dominadas perceber as injustiças sociais de maneira crítica' (FREIRE, 1981) $[\ldots]$
Diante do exposto podemos perceber o por que Paulo Freire incomoda.
O direito à educação igualitária incomoda
O grito e a ação do homem incomoda
A comunhão em busca da liberdade incomoda
A educação libertadora incomoda (M.E., 2019).28

Analisando o trecho acima, percebemos a tentativa da licencianda de, através das ideias de Paulo Freire, reafirmar a necessidade de se combater o conservadorismo, o antiintelectualismo e seus malefícios frente a uma Educação crítica, que promove a liberdade. Tal conservadorismo, no âmbito dos saberes históricos, tem se apresentado sob a forma dediscursos negacionistas e revisionistas, aos quais devemos estar atentos, tendo cautela inclusive para não confundi-los, como nos alerta Enzo Traverso (2012).

Dialogando com o autor italiano, compreendemos que os discursos negacionistas são aqueles que, como sugere o termo, negam fatos e processos históricos, como o holocausto nos exemplos trazidos por Traverso (2012).

Quanto ao revisionismo, o autor nos alerta para a necessidade de diferenciá-lo das revisões historiográficas, que podem ser legítimas - fecundas ou discutíveis - e até mesmo necessárias (TRAVERSO, 2012, p. 157). Nestes casos, elas se dão de forma natural, frente à descoberta de novas fontes históricas ou à mudança de paradigma interpretativo. No entanto, aquelas revisões que implicam uma viragem ético-política na nossa forma de olhar o passado são as que qualificamos negativamente de revisionismo, por serem profundamente nefastas (TRAVERSO, 2012, p. 157). Frequentemente, tais revisões

ultrapassam as fronteiras da historiografia enquanto disciplina científica para tocarem um campo mais vasto, o da relação que cada país estabelece com o seu passado, aquilo

27 Trecho de registro produzido por um licenciando referente à última aula do curso.

28 Trecho de registro produzido por uma licencianda referente à terceira aula do curso. 
que Habermas definiu através de uma fórmula notável, como o uso público da bistória. Dito de outra maneira, essas revisões questionam, para lá de uma interpretação dominante, uma consciência histórica partilhada, uma responsabilidade coletiva a respeito do passado (TRAVERSO, 2012, p. 160).

É neste sentido que observamos atualmente um revisionismo acerca da história da Ditadura Militar brasileira. Essas releituras do passado possuem o objetivo político de minimizar os males daquele período, além de legitimar os atuais avanços conservadores, sendo incentivadoras da repressão e censura. Para além disso, tal revisionismo também disputa a memória pública acerca da Ditadura implementada no Brasil a partir de 1964, contrariando a historiografia que denuncia seus crimes.

É o caso das narrativas produzidas pelo Brasil Paralelo, que, como mencionamos anteriormente, afirmam ir contra o que ensinam os professores de História. Dessa forma, tais narrativas questionam a consciência histórica partilhada e a responsabilidade coletiva da nação acerca daquele período de supressão de liberdades e torturas.

É devido a tais discursos conservadores que observamos tamanha a dificuldade dos docentes em tratar desses temas, agora tomados como sensíveis, em sala de aula. As narrativas negacionistas e revisionistas invadem os espaços educacionais descredibilizando os saberes dos professores e até mesmo a própria escola enquanto um ambiente produtor e disseminador de conhecimento. Contudo, frente a esses ataques, devemos elaborar táticas de sobrevivência que visem uma educação crítica, dialógica e libertadora.

Foi buscando cumprir tais objetivos e estimulá-los que produzimos a seguinte História em Quadrinhos, enquanto um dos frutos de nosso projeto de pesquisa - o qual também tinha por objetivo a elaboração de materiais didáticos sobre temas considerados sensíveis pelos alunos do curso realizado em 2019. 
História em Quadrinhos produzida pela pesquisa ${ }^{29}$

Imagem 7

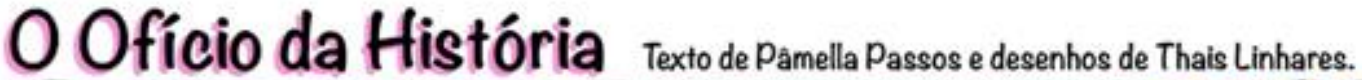
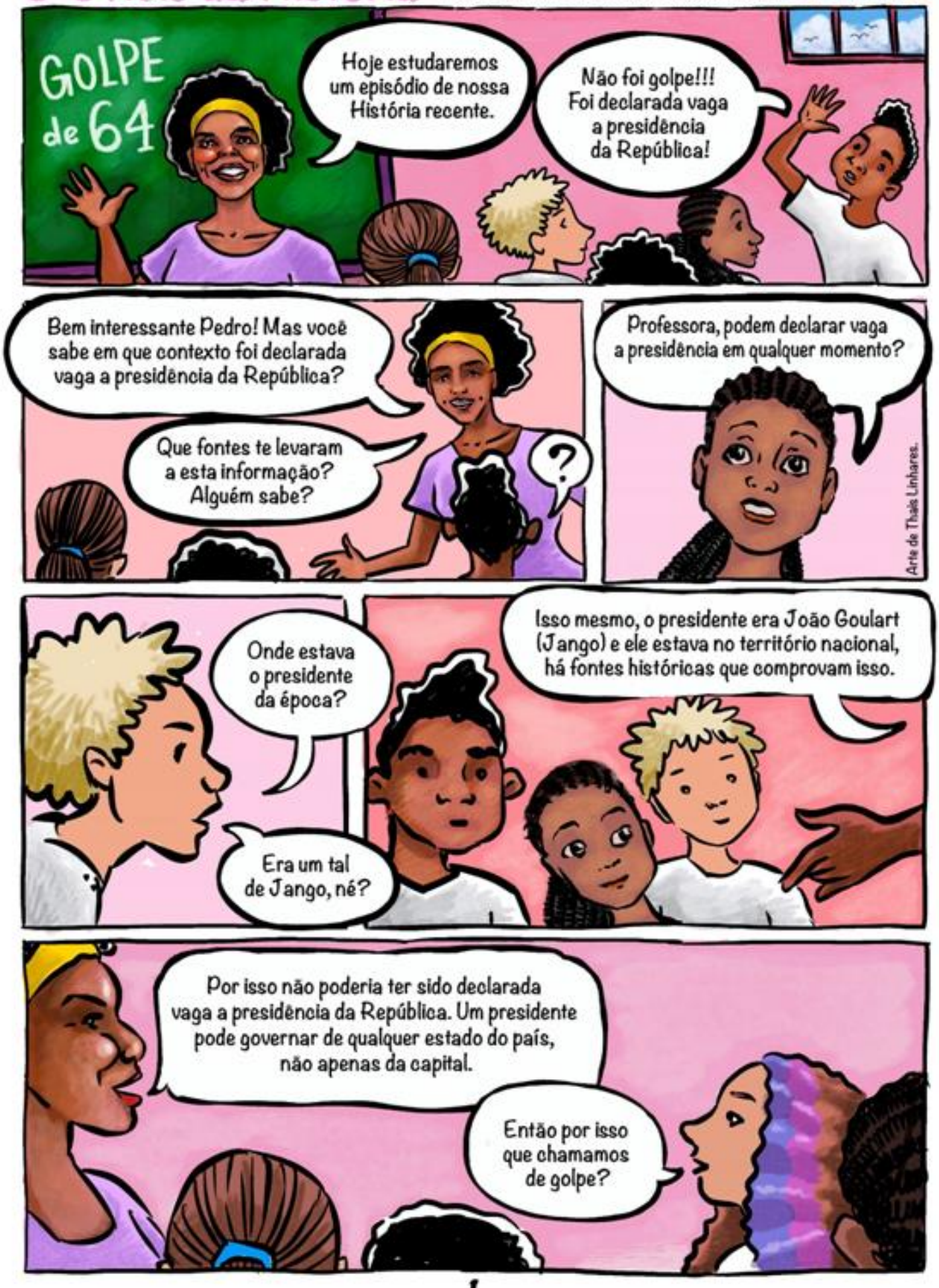

29 Publicado em: https://www.facebook.com/ensino.dh 
Imagem 8
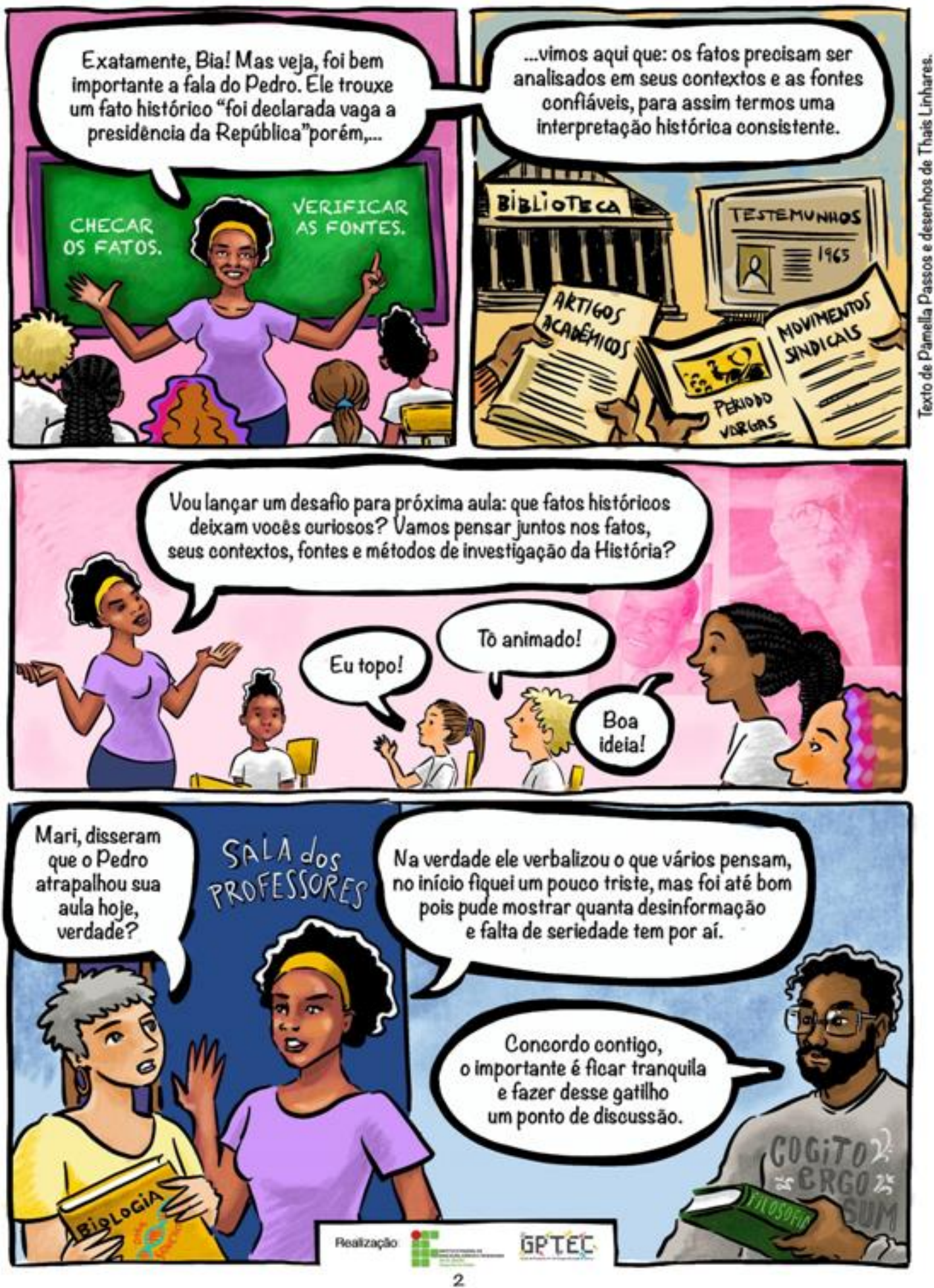

A História em Quadrinhos (HQ) ilustra uma cena, infelizmente, muito comum no cotidiano escolar atual: uma professora de História sendo interrompida por um aluno que acredita não ter havido um golpe militar no Brasil. Como podemos observar na ilustração, o aluno não questiona ou abre um debate; ele interrompe a professora lançando uma afirma- 
tiva, buscando assim criar um clima de descrédito da docente.

Nesta situação cotidiana, a professora precisou criar uma tática para enfrentar a circunstância. Assim, ela usou da objeção do aluno para mostrar que devemos sempre checar as fontes históricas e analisar os fatos em seus devidos contextos, estando atentos aos métodos de investigação da historiografia. Além disso, mantendo a calma, ela suscitou o diálogo acerca desses temas com toda a turma, como posteriormente seu colega de profissão também a aconselhou neste sentido.

Como a professora Mari relata à sua colega de biologia, no início ela ficou "um pouco triste", mas buscou conduzir a situação de modo a dialogar com toda a turma e avançar na questão. Sabemos que muitas professoras e professores no Brasil de hoje se sentem extremamente tristes, desrespeitados e desvalorizados, esta História em Quadrinhos é também para dar visibilidade a esta luta cotidiana.

Em Pedagogia dos Sonhos Possiveis (2014), Paulo Freire convoca os educadores progressistas à responsabilidade ética de revelar as situações de opressão (FREIRE, 2014, p. 49). Num contexto de avanço conservador, tal movimento está sendo visto como doutrinação e, por isso, sendo duramente atacado. Como nos aponta o educador brasileiro - referência mundial em sua área e alçado a inimigo pelos discursos que atacam a educação democrática - o objetivo das doutrinas liberais é de impor limites à educação, transformando-a em mero treinamento.

É impossível existir sem sonho, afirma Paulo Freire, e precisamos sonhar com mudanças, ainda que elas estejam distantes. Ao longo deste artigo buscamos afirmar o ofício do historiador e o papel do ensino da História enquanto uma ferramenta de resistência e produção de transformações sociais.

Os ataques sofridos por professoras e professoras de História, formados ou em formação atingem diretamente nossos sonhos, mas como afirma Paulo Freire:

Precisamos vislumbrar nosso trabalho com base em uma noção de perspectiva e história. Nossa luta de hoje não significa que necessariamente conquistaremos mudanças, mas sem que haja essa luta, hoje, talvez as gerações futuras tenham de lutar muito mais. A história não termina em nós: ela segue adiante (FREIRE, 2014, p. 57).

Que possamos seguir a diante escovando a História a contrapelo!

\section{Referências}

ANDRADE, Nívea. Práticas escolares como táticas criadoras: os praticantes nas tessituras de currículos.2011. Dissertação (Doutorado em Educação) - Programa de Pós-Graduação em Educação, Universidade do Estado do Rio de Janeiro, Rio de Janeiro.

ASSIS, Denise de. Propaganda e Cinema a Serviço do Golpe (1962-1964). Rio de Janeiro: Mauad/FAPERJ, 2001.

BASILIO, Ana Luiza. SC: Professor é demitido após trabalhar texto sobre tortura na ditadura militar. CartaCapital, 21 de maio de 2019. Educação.

BENJAMIN, Walter. Magia e técnica, arte e política: ensaios sobre literatura e história da cultura. São Paulo: Brasiliense, 1994. - Obras escolhidas volume 1.

BOAL, Augusto. Teatro do Oprimido e Outras Poéticas Políticas. Rio de Janeiro: Civilização Brasileira, 1991. 
BURKE, Edmund. Reflexões sobre a revolução em França. Brasília: Editora Universidade de Brasília, 1982.

CERTEAU, Michael de. A invenção do cotidiano: 1. Artes de fazer. Petrópolis, RJ: Vozes, 2012. FELIX, Mayalu. A NARRATIVA MÍTICA DE ZUMBI DOS PALMARES. Disponível em:

http://www.palmares.gov.br/wp-content/uploads/2020/02/A-NARRATIVA-M\%C3\%8DTICADE-ZUMBI-DOS-PALMARES.pdf Acesso em: 14 mai. 2020.

FREIRE, Paulo. Pedagogia do Oprimido. Rio de Janeiro: Paz e Terra, 1987. . Pedagogia dos sonhos possíveis. São Paulo: Paz e Terra, 2014.

HIRSCHMAN, Albert. A Retórica da intransigência: perversidade, futilidade, ameaça. São Paulo: Cia das Letras, 1992.

LEI No 7.668". www.planalto.gov.br. 22 de agosto de 1988. Disponível em: http://www.planalto.gov.br/ccivil_03/LEIS/L7668.htm Acesso em 07 mai. 2020.

MENDONÇA, Amanda. Projetos para Educação brasileira: da retórica conservadora ao pânico moral. Revista Communitas, Volume 2, Número Especial, Páginas 106-120, 25 nov. 2018.

PASSOS, Pâmella. Vozes a favor do golpe! O discurso anticomunista do Ipês como materialidade de um projeto de classes. Rio de Janeiro: Editora Mórula, 2017.

; GUIGUES, Luciana. O Ensino de História em Tempos de Conservadorismos: alguns desafios na formação de professores. Revista Escritas. Araguaína,Volume 12, Número 2, 2020 (No prelo).

PENNA, Fernando. 0 ódio aos professores. In: Ação Educativa Assessoria, Pesquisa e Informação (Org.). A Ideologia do Movimento Escola Sem Partido. São Paulo: Ação Educativa, 2016.

O Escola sem Partido como chave de leitura do fenômeno educacional. In: FRIGOTTO, Gaudêncio (Org.). Escola "sem" partido: esfinge que ameaça a educação e a sociedade brasileira. Rio de Janeiro: UERJ/LPP, 2017.

SANTOS, Rayani Mariano dos. A mobilização de questões de gênero e sexualidade e o fortalecimento da direita no Brasil. Agenda Política. Revista de Discentes de Ciência Política da Universidade Federal de São Carlos. São Carlos,Volume 8, Número 1, Páginas 50-77, 2020.

SEPULVEDA, Jose Antonio; SEPULVEDA, Denize. 0 pensamento conservador e sua relação com práticas discriminatória na educação: a importância da laicidade. Revista Teias. Volume 17, Número 47, Páginas 141-154, 2016.

Conservadorismo e Educação escolar: um exemplo de exclusão. MovimentoRevista de Educação. Volume 3, Número 5, Páginas 76-107, 2016.

o Conservadorismo e seus impactos no currículo escolar. Currículo sem Fronteiras. Volume 19, Número 3, Páginas 868-892, set./dez. 2019,

TRAVERSO, Enzo. O passado, modos de usar: História, Memória e Política. Lisboa: Edições Unipop, 2012. 